\section{Nonmelting-flesh Trait in Peaches Is Not Related to Low Ethylene Production Rates}

\author{
Ernesto A. Brovelli, Jeffrey K. Brecht, and Wayne B. Sherman \\ Horticultural Sciences Department, Institute of Food and Agricultural Sciences, \\ University of Florida, Gainesville, FL 32611-0690
}

\author{
Charles A. Sims \\ Food Science and Human Nutrition Department, Institute of Food and \\ Agricultural Sciences, University of Florida, Gainesville, FL 32611-0370
}

Additional index words. Prunus persica, maturation, ripening, respiration, climacteric

\begin{abstract}
The notion that ethylene production levels in nonmelting-flesh (NMF) peach (Prunus persica L.) fruit are normally lower than those in melting-flesh (MF) fruit is refuted in our study. In fact, NMF fruit ('Oro A' and FL 86-28C) usually produced higher levels of ethylene than did MF fruit (FL 90-20 and 'TropicBeauty'). In both MF and NMF peaches, the rate of ethylene production, rather than the respiration rate, provided a good indication of the developmental stage of the fruit at harvest. Ethylene content in fruit on the tree followed a climacteric pattern, with the level in 'Oro A' (NMF) and FL 90-20 (MF) peaking at 50 and $12 \mu \mathrm{L} \cdot \mathrm{L}^{-1}$, respectively. The respiratory climacteric was not apparent in either 'Oro A' or FL 90-20, and levels of $\mathrm{CO}_{2}$ were similar in both genotypes.
\end{abstract}

Along with sensory and compositional changes, peaches exhibit a rise in their respiratory activity during ripening (Amoros et al., 1989; Lim and Romani, 1964; Looney et al., 1974). This rise follows the typical climacteric pattern (Lill et al., 1989; Looney et al., 1974). Relative to other horticultural commodities, peaches have a moderate respiration rate during ripening, with $\mathrm{CO}_{2}$ production rates ranging from 59 to $102 \mathrm{mg} \cdot \mathrm{kg}^{-1} \cdot \mathrm{h}^{-1}$ at $20{ }^{\circ} \mathrm{C}$ (Hardenburg et al., 1986; Kader and Mitchell, 1989). Variations in the rate of respiration have been observed for different varieties, maturities, climatic conditions, and cultural practices (Kader and Mitchell, 1989).

A climacteric surge in the production of ethylene is also observed during the ripening of peaches (Amoros et al., 1989; Looney et al., 1974; Miller et al., 1988; Tonutti et al., 1991) and nectarines (Brecht and Kader, 1984a, 1984b), and the level can be 10-fold that in preclimacteric fruit (Miller et al., 1988). According to Amoros et al. (1989), the peak levels of ethylene and $\mathrm{CO}_{2}$ occur at about the same time. The rate of ethylene production during ripening of peaches reportedly ranges from 0.1 to $140 \mu \mathrm{L} \cdot \mathrm{kg}^{-1} \cdot \mathrm{h}^{-1}$ at $20^{\circ} \mathrm{C}$ (Kader and Mitchell, 1989). Ethylene production increases with a rise in temperature (Kader and Mitchell,

Received for publication 23 Apr. 1998. Accepted for publication 6 Oct. 1998. Univ. of Florida Agricultural Experiment Station Journal Series no. R06121. The cost of publishing this paper was defrayed in part by the payment of page charges. Under postal regulations, this paper therefore must be hereby marked advertisement solely to indicate this fact.

HortScience, Vol. 34(2), April 1999
Plant material and classification of the fruitfor off-the-tree measurements: This study was initiated in 1994 and was repeated, with modifications, in 1995. The plant material consisted of two genotypes each of MF (FL 90-20 and 'TropicBeauty') and NMF fruit ('Oro A' and FL 86-28C). Fruit from all four genotypes were obtained from the Teaching Orchard, Horticultural Sciences Dept., Univ. of Florida, Gainesville. While unrelated by inbreeding coefficients, the genotypes are selections from the Florida breeding program and represent a rather narrow genetic base. Each NMF genotype was paired with a MF genotype of comparable maturity date. In 1994, fruit were harvested on three dates at intervals of $7 \mathrm{~d}$. On each date, only those fruit whose ground color was representative of the average ground color for each genotype on that harvest date were selected. The fruit collected at each harvest were considered to represent a maturity category. Ethylene production was measured for a sample of fruit from each maturity category as described below.

In 1995, fruit were harvested on two dates 1 week apart. Limited quantity of fruit did not allow a second harvest for 'TropicBeauty'. Unlike 1994, harvesting was nonselective and all fruit on two trees per harvest were collected. Once in the laboratory, the fruit were divided into six classes based on diameter scale, using 0.16-cm increments. FL 90-20, FL 86-28C, and 'TropicBeauty' have fruit innately larger than those of 'Oro A'; thus, the initial size class was 5.24 through $5.40 \mathrm{~cm}$ for the first three genotypes and 4.60 through 4.76 $\mathrm{cm}$ for 'Oro A'. Since, in 1994, diameter measurements in situ showed that diameter continued to increase as the fruit matured, the scheme used in 1995 resulted in a wider range of maturity levels.

Ethylene production and respiration rate were measured for a sample of fruit from each diameter class within each harvest as described below. Measurements were interrupted when fruit showed symptoms of decay.

Off-the-tree determination of ethylene production and respiration rate. Ethylene production and respiration rate were measured in 1.75-L glass jars at $20{ }^{\circ} \mathrm{C}$ and $80 \%$ relative humidity. Initial measurements were made 24 $\mathrm{h}$ after harvest and then daily. Three replicates of three fruit each were sealed in the jars for 1 h. For headspace sampling, syringes were inserted through rubber septa in the lid. Ethylene samples were analyzed using a gas chromatograph equipped with an activated alumina-packed column and a photoionization detector. The $\mathrm{CO}_{2}$ samples were analyzed using a gas chromatograph equipped with a packed column (Porapak Q; Supelco, Bellefonte, $\mathrm{Pa}$.) and a thermal conductivity detector.

On-the-tree determinations of internal ethylene and $\mathrm{CO}_{2}$ levels. For the genotypes FL 90-20 and 'Oro A', the gas collection technique described by Banks (1983) was used to measure the ethylene and $\mathrm{CO}_{2}$ levels while the fruit were still attached to the tree. 

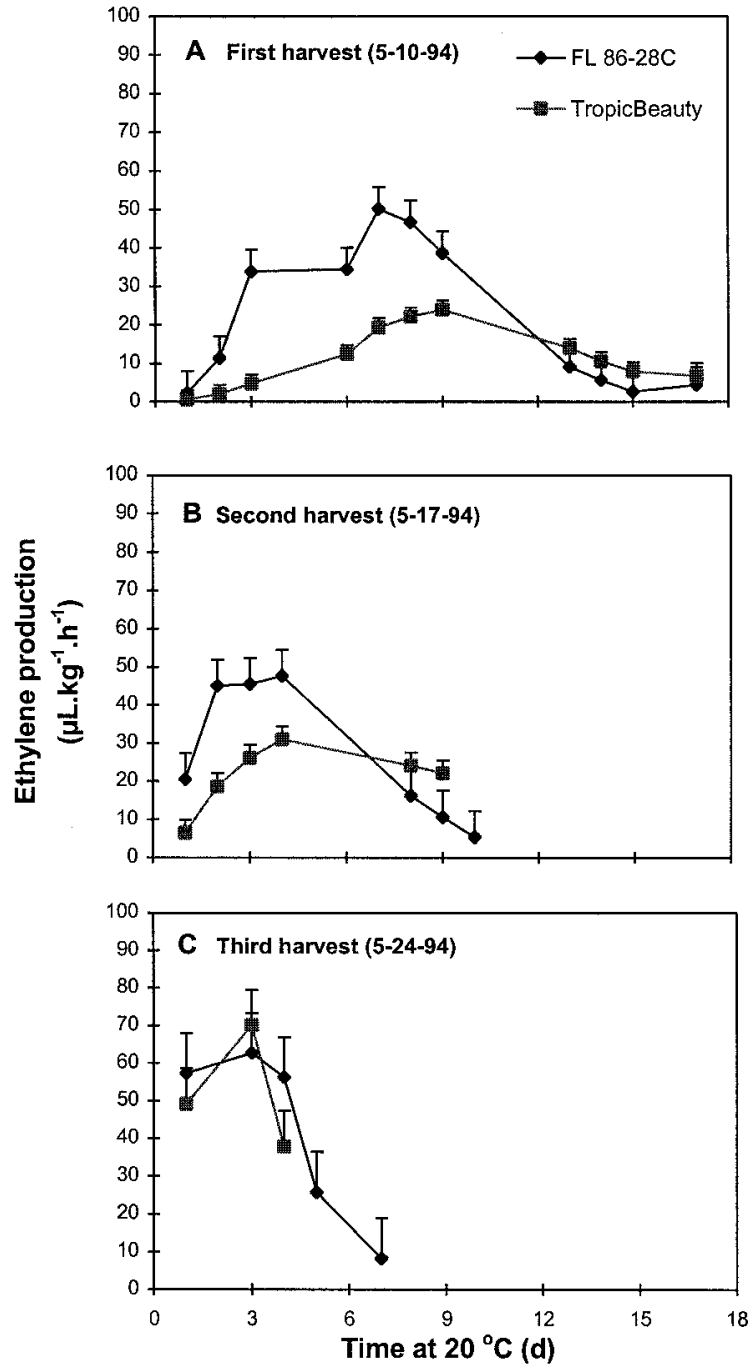
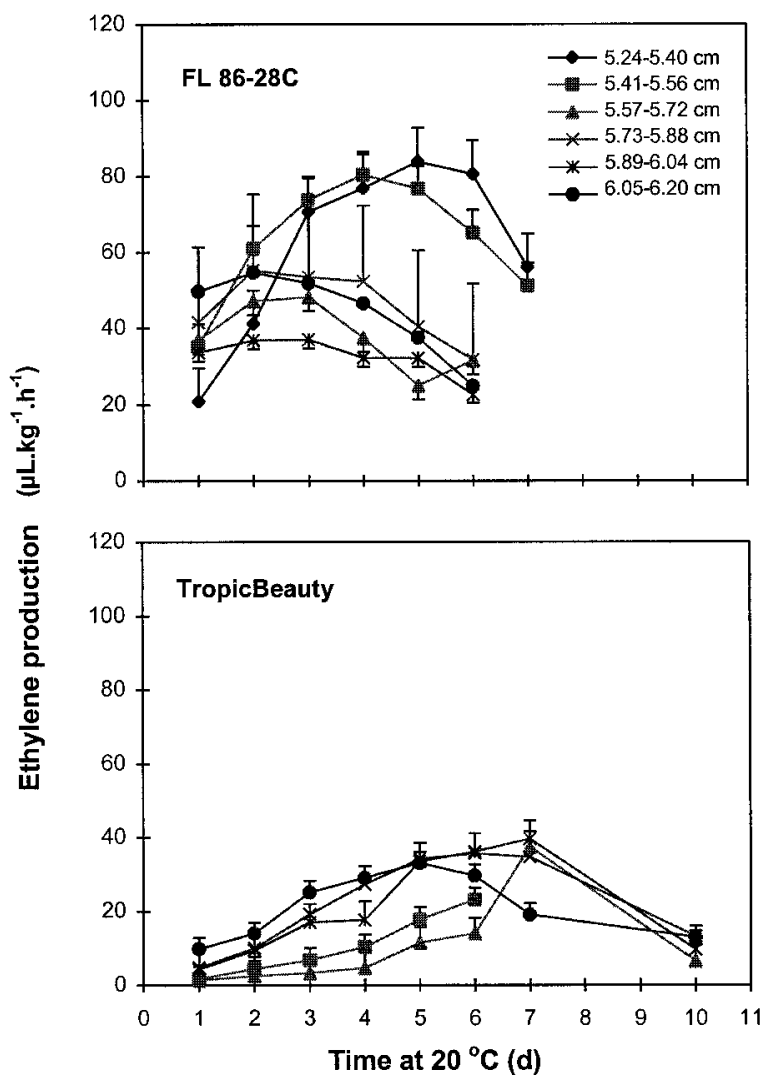

Fig. 2. Ethylene production at $20^{\circ} \mathrm{C}$ of six diameter classes of FL 86-28C (NMF) and 'TropicBeauty' (MF) peaches following the first 1995 harvest. Each value is the mean for three replicates of three fruit each. Vertical bars are standard errors for each genotype.

Fig. 1. Ethylene production at $20^{\circ} \mathrm{C}$ following sequential harvests in 1994 of FL 86$28 \mathrm{C}(\mathrm{NMF})$ and 'TropicBeauty' (MF) peaches. Each value is the mean for three replicates of three fruit each. Vertical bars are standard errors for each genotype.

A set of 16 uniformly sized fruit on three trees were designated for the measurement of ethylene or $\mathrm{CO}_{2}$ and labeled accordingly. A rubber serum stopper (size 14; Fisher Scientific, Pittsburgh) was attached to the fruit's exocarp in the cheek area using a noncorrosive silicon rubber adhesive (3140 RTV Coating; Dow Corning, Midland, Mich.), which does not produce ethylene and is not injurious to the peel(P.D. Petracek, personal communication). Prior to attachment to the fruit, the stoppers were autoclaved for an hour to drive off all ethylene. Gas samples were removed through the septa with syringes and analyzed by gas chromatography as described for off-the-tree measurements.

\section{Results and Discussion}

The pattern of ethylene production over time for fruit harvested in 1994 reflected the different developmental stages at which the fruit were harvested. Upon collection, fruit of FL 86-28C and 'TropicBeauty' from the first, second, and third harvests were at the preclimacteric, climacteric rise, and climacteric peak, respectively (Fig. 1). 'Oro A' and FL 90-20 fruit exhibited similar patterns of ethylene production (data not shown).

The pattern of ethylene production for fruit of FL 86-28C and 'TropicBeauty' from the first harvest in 1995 was a good indicator of the developmental stage as related to diameter (Fig. 2). In general terms, fruit from the second harvest, whether MF or NMF, were at a more advanced phase in their ethylene production pattern than those from the first harvest (data not shown).

The climacteric peak of ethylene production was distinctively higher in the two NMF genotypes than in the two MF genotypes (Figs. 1 and 2). Data for 'Oro A' and FL 90-20 (not shown) were similar to those for FL 86-28C and 'TropicBeauty'. At the third harvest of 'TropicBeauty' and FL 86-28C, ethylene production was similar for both genotypes, but the climacteric was not well defined and trends were difficult to compare (Fig. 1). The higher levels of ethylene production in NMF fruit contrast with reports by El-Agamy et al. (1981) and Biggs et al. (1982) that the biological basis of the slow-softening trait (NMF) in peaches was a reduced capability for ethylene production.

Fruit developmental stage and respiratory drift were not clearly related (Fig. 3). The maximum rate of $\mathrm{CO}_{2}$ production observed for NMF genotypes ranged from 40 to 100 $\mathrm{mL} \cdot \mathrm{kg}^{-1} \cdot \mathrm{h}^{-1}$ and that for MF genotypes from 40 to $50 \mathrm{~mL} \cdot \mathrm{kg}^{-1} \cdot \mathrm{h}^{-1}$, but a climacteric respiratory pattern was not readily apparent.

Ethylene production by fruit on the tree followed a climacteric pattern for both 'Oro A' and FL 90-20 (data not shown). However, the same distinction between MF and NMF fruit noted in ethylene production off the tree was also apparent in the measurements on the tree. The average peak level of ethylene was $50 \mu \mathrm{L} \cdot \mathrm{L}^{-1}$ for 'Oro A' (NMF) and $12 \mu \mathrm{L} \cdot \mathrm{L}^{-1}$ for FL 90-20 (MF). Levels of $\mathrm{CO}_{2}$ for fruit on the tree were similar in both genotypes. Unlike the production of ethylene, which showed a clear climacteric trend, the levels of $\mathrm{CO}_{2}$ tended to fluctuate more, making the respiratory climacteric indefinite (data not shown).

According to our observations, ethylene production by NMF fruit both on and off the plant is higher than, or at best similar to, that of 

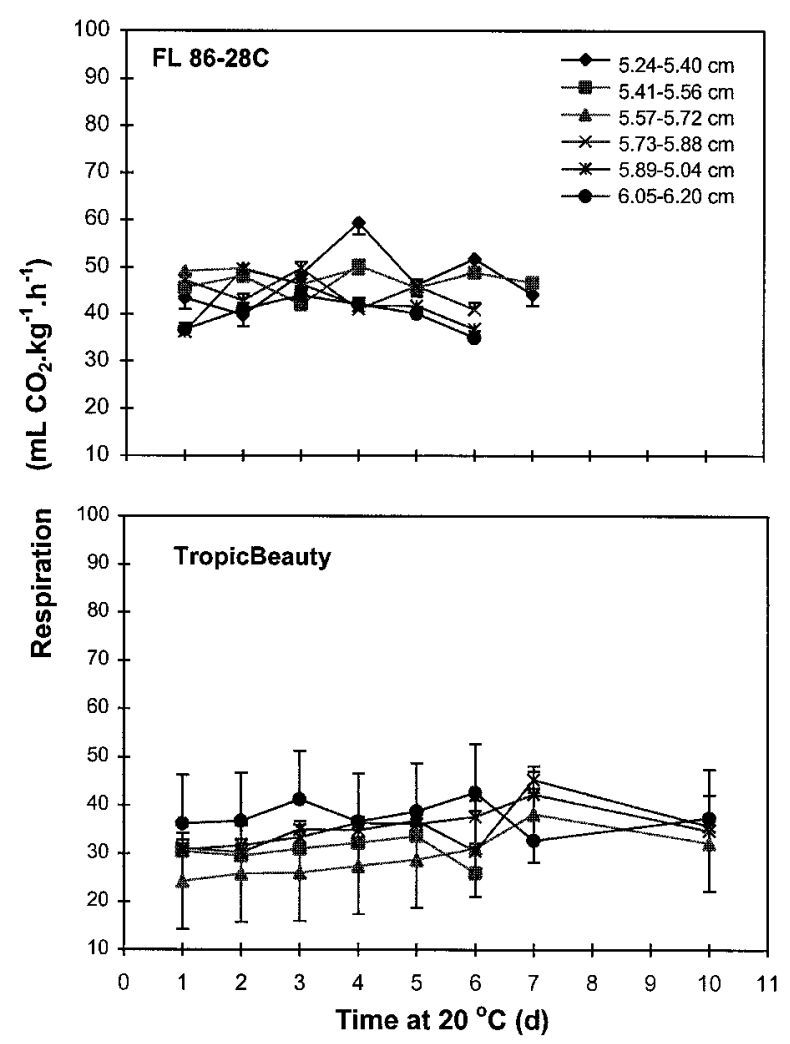

Fig. 3. Respiration rate at $20^{\circ} \mathrm{C}$ of six diameter classes of FL 86-28C (NMF) and 'TropicBeauty' (MF) fruit following the first 1995 harvest. Each value is the mean for three replicates of three fruit each. Vertical bars are standard errors for each genotype.

MF fruit, thus refuting the hypothesis that low levels of ethylene production are responsible for the NMF trait in peaches.

\section{Literature Cited}

Amoros, A., M. Serrano, F. Riquelme, and R. Romojaro. 1989. Levels of ACC and physical and chemical parameters in peach development. J. Hort. Sci. 64:673-677.

Banks, N.H. 1983. Evaluation of methods for determining internal gases in banana fruit (Musa acuminata x Musa balbisiana). J. Expt. Bot. 34:871-879.

Biggs, RH., S.Z.A. El-Agamy, and M.M. Aly. 1982. Ethylene production by mature peach fruit. HortScience 17:62. (Abstr.)

Brecht, J.K. and A.A. Kader. 1984a. Ethylene production by 'Flamekist' nectarines as influenced by exposure to ethylene and propylene. J. Amer. Soc. Hort. Sci. 109:302-305.

Brecht, J.K. and A.A. Kader. 1984b. Regulation of ethylene production by ripening nectarine fruit as influenced by ethylene and low temperature. J. Amer. Soc. Hort. Sci. 109:869-872.

Brecht, J.K. and A.A. Kader. 1984c. Description and postharvest physiology of some slow-ripening nectarine genotypes. J. Amer. Soc. Hort. Sci. 109:596-600.

Brecht, J.K. and A.A. Kader. 1984d. Ethylene production by fruit of some slow-ripening nectarine genotypes. J. Amer. Soc. Hort. Sci. 109:763767.

Brovelli, E.A., J.K. Brecht, W.B. Sherman, and C.A. Sims. 1995. Quality profile of fresh market melting and nonmelting peach fruit. Proc. Fla. State Hort. Soc. 108:309-311.

Brovelli, E.A., J.K. Brecht, W.B. Sherman, and
C.A. Sims. 1998. Potential maturity indices and developmental aspects of melting- and nonmelting-flesh peach genotypes for the fresh market. J. Amer. Soc. Hort. Sci. 123:438444.

Brovelli, E.A., J.K. Brecht, W.B. Sherman, C.A. Sims, and J.M. Harrison. 1999. Sensory and compositional attributes of melting and nonmelting-flesh peaches for the fresh market. J. Sci. Food Agr. (In press.)

El-Agamy, S.Z.A., M.M. Aly, and R.H. Biggs. 1981. Ethylene as related to fruit ripening in peaches. Proc. Fla. State Hort. Soc. 94:284-289.

Hardenburg, R.E., A.E. Watada, and C.Y. Wang. 1986. The commercial storage of fruits, vegetables, and florist nursery stocks. U.S. Dept. Agr. Hdbk. 66, Washington, D.C.

Kader, A.A., M.A. El-Goorani, and N.F. Sommer. 1982. Postharvest decay, respiration, ethylene production, and quality of peaches held in controlled atmospheres with added carbon monoxide. J. Amer. Soc. Hort. Sci. 107:856-859.

Kader, A.A. and F.G. Mitchell. 1989. Postharvest physiology, p. 158-164. In: J.H. LaRue and R.S. Johnson (eds.). Peaches, plums and nectarines. Growing and handling for fresh market. Univ. of California, Oakland.

Ke, D., L. Rodriguez-Sinobas, and A.A. Kader. 1991. Physiological responses and quality attributes of peaches kept in low oxygen atmospheres. Scientia Hort. 47:295-303.

Kubo, Y., A. Inaba, and R. Nakamura. 1990. Respiration and $\mathrm{C}_{2} \mathrm{H}_{4}$ production in various crops held in $\mathrm{CO}_{2}$-enriched atmospheres. J. Amer. Soc. Hort. Sci. 115:975-978.

Lester, D.R., W.B. Sherman, and B.A. Atwell. 1996. Endopolygalacturonase and the melting flesh (M) locus in peach. J. Amer. Soc. Hort. Sci. 121:231-235.

Lill, R.E., E.M. O’Donoghue, and G.A. King. 1989. Postharvest physiology of peaches and nectarines. Hort. Rev. 11:413-452.

Lim, L. and R.J. Romani. 1964. Volatiles and the harvest maturity of peaches and nectarines. J. Food Sci. 29:246-253.

Looney, N.E., W.B. McGlasson, and B.G. Coombe. 1974. Control of fruit ripening in peach Prunus persica: Action of succinic acid-2, 2-dimethylhydrazide and 2-chloroethyl phosphonic acid. Austral. J. Plant Physiol. 1:77-86.

Miller, A.N., B.A. Krizek, and C.S. Walsh. 1988. Whole-fruit ethylene evolution and ACC content of peach pericarp and seeds during development. J. Amer. Soc. Hort. Sci. 113:119124.

Tonutti, P., P. Casson, and A. Ramina. 1991. Ethylene biosynthesis during peach fruit development. J. Amer. Soc. Hort. Sci. 116:274-279. 